\title{
Can environmental performance rating programmes succeed in Africa?: an evaluation of Ghana's AKOBEN project
}

Article

Accepted Version

Darko-Mensah, A. and Okereke, C. (2013) Can environmental performance rating programmes succeed in Africa?: an evaluation of Ghana's AKOBEN project. Management of Environmental Quality, 25 (5). pp. 599-618. ISSN 1477-7835 doi: https://doi.org/10.1108/MEQ-01-2012-0003 Available at https://centaur.reading.ac.uk/33199/

It is advisable to refer to the publisher's version if you intend to cite from the work. See Guidance on citing.

Published version at: http://www.emeraldinsight.com/journals. htm? issn=1477-7835\&volume=24\&issue $=5$

To link to this article DOI: http://dx.doi.org/10.1108/MEQ-01-2012-0003

Publisher: Emerald Group Publishing Limited

All outputs in CentAUR are protected by Intellectual Property Rights law, including copyright law. Copyright and IPR is retained by the creators or other copyright holders. Terms and conditions for use of this material are defined in the End User Agreement.

www.reading.ac.uk/centaur 
Central Archive at the University of Reading

Reading's research outputs online 


\title{
Can Environmental Performance Rating Programmes Succeed in Africa?: an Evaluation of Ghana's AKOBEN Project
}

\begin{abstract}
Purpose: The purpose of the article is to describe and analyse Ghana's AKOBEN programme which is the first environmental performance rating and public disclosure programme in Africa. Furthermore, by means of a SWOT analysis, the article assesses the suitability of AKOBEN as a veritable tool for promoting good environmental governance in Ghana specifically and Africa in general.
\end{abstract}

Design/ methodology/approach: The description of the design, scope and operation of the AKOBEN programme is based on 42 semi structured interviews and series of informal interactions with officials of Ghana's Environmental Protection Agency (EPA) - the organisation that runs the AKOBEN project, industry participants, civil society representatives and other stakeholders. This extensive interaction with relevant actors and stakeholders and the analysis of extant literature on environmental disclosure projects provided the basis for a Strength, Weakness, Opportunity and Threat (SWOT) analysis of Ghana's AKOBEN programme.

Findings: AKOBEN possesses several elements that make it capable of being an effective environmental governance tool in Ghana. These include inter alia high level political support, comprehensive rating criteria and transparency in the design of the programme. However, certain weaknesses such as the absence of a specific legal and institutional framework among others could undermine the chances of the programme attaining its full potential. Other African countries can reasonably copy the AKOBEN model with success.

Originality/ Value- Assessment of Africa's first ever environmental rating programme provides insight that can help Ghana to consolidate on the strengths while addressing the weaknesses of the rating programme. Other African governments considering the establishment of similar rating programme can learn a lot from the analysis of Ghana’s EPA's AKOBEN programme. 


\section{Introduction}

In November 2010, Ghana’s Environmental Protection Agency (EPA) launched its first official environmental performance rating and public disclosure programme, known as AKOBEN. In doing so, Ghana became the first country in sub-Saharan Africa to initiate a fully government sponsored environmental performance rating programme. The term 'AKOBEN' is a traditional Ghanaian symbol which means 'vigilance' and 'wariness'. At the launch of the premier disclosure in 2009, 60 companies made up of 11 mining and 49 manufacturing firms participated. About the same number of industries participated in the second disclosure period. According to EPA officials the third and current programme (the results of which are yet to be released at the time of writing), covers about 100 firms. The Mbedi travel and business directory for Ghana has about 106 manufacturing companies listed (www.mbedni.com).

This rating project and the choice of name are both consistent with the recent effort of the Ghanaian government to improve governance on various spheres of public and private enterprise (NDPC, 2010). Similarly, the programme apparently represents Ghana's EPA's attempt to embrace the recent global trend in environmental governance which involves increasing transparency (Gupta, 2010), accountability (Haufler, 2010) and public participation (Gupta, 2008). The AKOBEN programme merits close study because it marks a new phase in environmental regulation in Ghana (and in Africa) which previously was done almost entirely through the use of command and control instruments. These instruments have often been considered as ineffective because of the limited political will to prioritise the environment and poor capabilities for monitoring and enforcement (Domfeh, 2003).

Environmental Performance Rating and Disclosure programmes (EPRD) are still in their early years in most developing countries so pronouncements on their impact must be tentative. 
Initial studies suggest they have been partially successful in a number of developing countries like Indonesia, China, India, Vietnam and Philippines (Afsah et al, 1997; Blackman et al., 2004; Wang et al., 2004; Powers et al., 2008). However, other accounts have shown that the impact of these initiatives is very limited as they remain beset by favouritism, weak governance and poor scoping guidelines (Haufler, 2010; Gupta, 2010). It is therefore essential to carefully explore the specific conditions that either enable or limit the effectiveness of EPRD in developing countries. Although still in its formative stage, an analysis of the first ever EPRD in Africa is warranted not the least because while they are all classified as 'developing countries', Africa has its own unique political, cultural and environmental characteristics all of which could influence outcome (Kolk and Lenfant, 2010).

The aim of this paper is to describe and analyse the AKOBEN programme including its scope, methodology and statutory arrangements. The description and analysis draw on documentary evidence and extensive interaction - involving informal and semi-structured interviews - with over 40 stakeholders including EPA officials, company managers and civil society leaders. These interactions and extant literature provided the basis for a Strength, Weakness, Opportunity and Threat (SWOT) analysis of Ghana's AKOBEN programme. Strengths refer to available resources that can give it an advantage relative to similar others. Weaknesses are shortcomings that can cause it to lose competitive advantage. Opportunities are external chances or elements that can be drawn upon to enhance performance or success. Threats are external elements in the environment that can harm the prospects of the policy or system. It is hoped that the research would help provide insight that would be beneficial to policy makers and other stakeholders in working towards improved environmental governance in Ghana. Other 
African governments considering the establishment of similar rating programmes can also learn a lot from the analysis of Ghana's EPA’s AKOBEN programme.

The rest of the paper is divided as follows. The next section provides a brief account of voluntary information discourse as a tool for environmental governance. Section 3 provides an account of the research method. Section 4 offers a description of the AKOBEN programme including its history, scope and rating methodology. This is followed first by a detailed SWOT analysis (section 5) and suggestions for change and improvement (section 6). The paper then ends with a short concluding statement.

\section{Voluntary Information Disclosure}

Information disclosure also known as "regulation by revelation" (Gupta, 2008 p. 2) is based on the principle of correcting information asymmetry arising from society's unawareness of the damage caused by individual polluters. Tietenberg (1998) and Lopez et al. (2009) suggest that information disclosure promotes interactions amongst firms, workers, community groups, consumers, financial markets and regulators. Furthermore, it is held that disclosure increases the cost of non compliance through channels that do not involve top down regulation (Lopez et al., 2009).

Most literature on public disclosure traces its history to the United States Toxic Release Inventory (US TRI) which was implemented in the late 1980’s (Tietenberg, 1998; Lopez et al., 2009; Dasgupta et al., 2007; Kathuria, 2009). This was in response to an increasing 'right to know' attitude amongst citizens and its practicality in addressing all toxic substances, whether conventionally regulated or not (Dasgupta et al., 2007 p. 98). The success of this programme in reducing pollution led to the development of two international trends. The first trend, akin to the US TRI, focuses on public reporting on emissions volumes and has largely been adopted by 
other industrialised countries like Canada, Europe and Australia. Other rapidly industrialising countries like South Korea and Mexico have also implemented this type of information disclosure. The second trend involves rating the environmental performance of industries and publicly disclosing the results. Environmental Performance Rating and Disclosure (EPRD), as it is commonly called, complements and strengthens conventional regulation (Dasgupta et al., 2007; Kathuria, 2009; Jin et al., 2010) through the use of performance benchmarks as a basis for rating.

In recent years, many developing countries have adopted EPRD in a bid to strengthen the governance of its environment with different degrees of success (Paliwal, 2006; Wang et al., 2004; Kathuria, 2009; Tietenberg, 1998). Pioneered by Indonesia in 1995, all disclosure programmes in developing countries comprise two separate components: a performance rating component and a public disclosure component. Indonesia's initiative was called Program for Pollution Control, Evaluation and Rating (PROPER). The programme was re-launched in 2002 with some amendments in methodology (Afsah, 2006). Other notable examples include the Philippines EPRD programme known as Industrial EcoWatch (launched in 1998) and China's Green Watch programme which began in 2000 with two municipalities as pilot cases and later extended to 22 municipalities in 2005. As stated, AKOBEN is African first and currently only EPRD.

\section{Methodology}

For the study, the authors adopted a qualitative approach relying on semi-structures interviews, extensive informal interaction and the analysis of documentary evidence. Primary data was obtained by the means of non-probability sampling (Berg, 2009 p. 109) across three main groups of respondents - the regulatory officials, manufacturing industries who participate in AKOBEN 
and public stakeholders. Selection was purposive in order to engage with those whose knowledge or activities were deemed relevant to the study. Five senior members of the AKOBEN team within EPA were interviewed. All of these have been very closely involved in the conception and implementation of the programme. In addition, three non-AKOBEN senior EPA officials were also interviewed. This was intended to gain the perspectives of experienced officers who had not been too closely involved with running the initiative. The authors also interviewed the EPRD independent expert that was consulted by the EPA in the course of designing the programme.

The manufacturing companies were categorised as foreign affiliate, multinational or local. Subsequently, five local firms, three multinational companies (MNC) and three foreign affiliates were selected based on quota sampling. The study focused on industries located within the Greater Accra region because one of the researchers lived in that area and was very familiar with those industries. Also, the region accommodates well over $60 \%$ of manufacturing industries in Ghana (EPA, 2004; www.mbendi.com). Choice of specific firms was strongly influenced by the pollution profile of their industrial sectors. Thus, companies within the food and beverage, oil and gas, textiles, paper and general manufacturing were the main focus. Respondents included very senior company managers including CEOs, Head of Health and Safety, Head of Quality Assurance and Environmental Service Managers. For wider stakeholders, we selected various members of the public that could have an interest in the AKOBEN programme (see table 1 for a summary of respondents). These included five banks, seven stock brokerage companies, two environmental NGOs, two insurance companies, three media organisations, two representatives from the Association of Ghana Industries (AGI) and one representative from the Ministry of Environment, Science and Technology (MEST). For the sake of anonymity the specific names or positions of respondents are not revealed. Accordingly, when quoting directly, the authors use 
codes (INV100 - INV4200) and in some cases provide a brief description of source to aid understanding.

\begin{tabular}{|l|l|}
\hline Affiliation & Quantity \\
\hline AKOBEN team & 5 \\
\hline EPA officials & 3 \\
\hline EPRD Expert & 1 \\
\hline Manufacturing Industries & 11 \\
\hline NGOs & 2 \\
\hline Banks & 4 \\
\hline Insurance Companies & 2 \\
\hline Association of Ghana Industries (AGI) & 3 \\
\hline Media & 3 \\
\hline MEST & 1 \\
\hline Stock Brokerage & 7 \\
\hline Total & $\mathbf{4 2}$ \\
\hline
\end{tabular}

Table 1. Summary of Respondents

Out of the 42 interviews conducted, 29 were face-to-face while 13 were done by telephone. Face-to-face interviews were conducted with all respondents from the manufacturing industries and the regulatory bodies with each lasting an average of one hour. Telephone interviews were mostly used for the public stakeholders to find out their awareness and perceptions about the programme. In some cases this was followed up with face-to-face interviews. Interviews lasted for between 15 to 30 minutes depending on awareness and interest. Only 8 interviewees allowed the interviews to be recorded. In the rest, the resort was hand notetaking with frequent clarification questions during and after the interview sessions. The questions focused on themes such as history, design, implementation, involvement, perceptions, awareness and impact. These themes also provided the basis for the analysis if the transcripts which was done by repetitive reading and manual coding (Saldana, 2009). 


\section{History of Disclosure Programmes in Ghana}

In 1999, Ghana’s EPA, the environmental regulatory body, decided to introduce disclosure as a complement to its environmental impact assessment (EIA) regime. This initiative focused on the mining companies, using reclamation bonds as a criterion for assessing their performance and publicly disclosing these rankings to the public. Following that, the EPA established an award system for manufacturing industries in 2000. This programme, known as the Continuous Environmental Improvement Award was based on rewarding firms who had continuously improved upon their environmental performance. The level of consistency had to be no less than three years. Though an impressive attempt, this award system was criticised on the basis of high level subjectivity resulting from the absence of a clearly defined method for assessment. Meanwhile, the EPA and the World Bank had began piloting an EPRD programme for manufacturing industries with 32 industries participating in the pilot project. Even though ratings were done to measure the environmental performance of these industries, the results were only made available to participating industries without any public disclosure as a follow up. Concerns and complaints received by participating industries contributed in the modification of the earlier pilot phase of the EPRD programme. Interview sources suggest the concerns raised by industries were mainly on three areas: (i) the system was only concerned with compliance to standards and guidelines set by the EPA; (ii) the rating system did not recognise industries' effort to solve other critical environmental problems; and (iii) some environmental quality standards such as Biochemical Oxygen Demand (BOD) and PH levels were too stringent to be attainable by industries.

After this pilot phase, the EPA team modified the system to one that combined both flexibility and stringency in addition to reflecting the Ghanaian concept of environment in its 
ratings. In revising the framework, the EPA organised several workshops for the industries with the aim of incorporating their concerns and getting their support. The result of this painstaking process which began in 1999 was the launch of the AKOBEN project in November 2010.

\section{Overview of Ghana's EPA AKOBEN programme}

The key aspects of the AKOBEN as with other EDRPs include the legal and institutional framework, rating criteria and methodology. Other critical aspects include the data collection and verification procedure, evaluation protocol and the process of disclosure (Gozun et al., 2011). Our description of AKOBEN covers these aspects.

\subsection{Legal backing and institutional framework}

The legal backing for EPRD in Ghana is the EPA Act 1994, Act 490 and the Environmental Assessment Regulations, 1999 L.I.1652. Section 2 (o) of Act 490 instructs the EPA to develop an environmental database with the aim of providing such information to the public. The 1992 National Environmental Policy also empowers the EPA to make "use of the most cost effective means to achieve environmental objectives including the use of incentives and public participation in environmental decision making” (National Environmental Policy, 1992, cited in Allotey et al., 2011). Unlike the Indonesian and Chinese EPRD programmes, which have specific institutional framework and legislation respectively, AKOBEN relies on the

aforementioned overarching provisions which do not explicitly highlight disclosure and can be loosely interpreted. 


\subsection{The AKOBEN team and the disclosure process}

AKOBEN programme brings together various departments within the EPA who play different roles throughout the entire rating and disclosure process (figure 1 below shows the organisational structure of the AKOBEN team). The day-to-day activities such as site inspections and field audits are carried out by officials from the mining and manufacturing departments, who make up the operations department of the EPA. The legal department handles the gazetting aspect of the disclosure process whereas the public affairs department is primarily responsible for the public disclosure component of the entire AKOBEN rating programme. Without a formal organisational unit of its own, the AKOBEN team therefore comprises officials from these various departments of EPA which meets to coordinate activities as and when the need arises.

Figure 1: Organisational structure of the AKOBEN team

Source: www.epaghanaakoben.org [Accessed on $29^{\text {th }}$ July, 2012]

The rating disclosure component is done in two phases: internal disclosure and the public disclosure. The latter is discussed in detail under section 5.7 thus this discussion will focus on the 
first phase. Prior to the internal disclosure phase, a preliminary workshop is organised for all participating companies to discuss the general performance of companies and universal issues. The internal disclosure is done after the initial ratings have been generated by the computerbased rating methodology. The operations arm, in this case, the manufacturing department of the EPA carries out this function by meeting with each company individually either on-site or at the EPA office. The primary aim of this disclosure is to inform the companies about their performance and to settle any disputes or discrepancies that might have arisen during the rating process. The internal disclosure provides a grace period (between 2-4 weeks) for companies to react to the ratings and justify any complaints or concerns. Interview responses from both companies' respondents and officials of the AKOBEN confirm that the grace period does not allow for an improvement or change in the initial ratings as is the case for China's Green Watch programme. In this regard, one may wonder if it is appropriate to use the term "grace" since it has no impacts on improving the performance of companies.

\subsection{Scope of AKOBEN programme}

Ghana's AKOBEN programme covers a broader scope than most of the other three EPRD programmes mentioned in the previous section. The scope comprises both environmental and social performance indicators. This reflects the Ghanaian concept of the "environment" which connotes "natural resources, social, cultural and economic conditions and the institutional environment in which decisions are made” (Strategic Environmental Assessment Report, 2004). It further shows that the programme does not merely adopt the parameters of its predecessors but that an attempt has been made to tailor it to suit the special characteristics and needs of the country. 
AKOBEN covers both air and water pollution substances in addition to non-conventional substances like mercury and lead. The focus on water and air pollution is similar to the approach adopted by Indonesian PROPER and Chinese EcoWatch. The programme, like the Indonesian PROPER focuses on the mining and manufacturing industries. It does not include service industries such as banks and tele-communications. Unlike the EcoWatch in China which was piloted in two municipalities, Ghana's AKOBEN covers industries operating in all 17 major towns in the country. However, as stated majority of the manufacturing industries sin Ghana are located in two cities - Accra the political capital city and Tema, the industrial capital. Selection of industries was random though EPA officials said they took cognisance of industry sector which were likely polluters (INV 600). Apparently to enhance comparison, the manufacturing industry is further grouped into sectors. There are a total of 21 sectors covering cement through pharmaceuticals to diary factories. Altogether, there are altogether 50 industrial facilities covered in the latest rating cycle. Of these nine are located in Accra while 20 were located in the Tema the area covered by this study. The mining sector on the other hand had all the 11 major mining companies participating in the AKOBEN. EPA officials say they plan to expand the programme in the near future to cover virtually all manufacturing industries operating in Ghana (INV 700).

\subsection{Data processing and credibility}

To ensure a high level of accuracy, ratings and evaluations are done by the use of a computerised system with the option of being able to change data at the initial input entry point (EPA, 2010). This minimises the level of human error and also ensures transparency. The flexibility of effecting changes at the initial entry point helps in rectifying any discrepancies that may arise during the internal disclosure with the industries. The key steps involved are: (i) data gathering, (ii) site audit for verification (iii) computerised evaluation and rating; (iv) report generation; and 
(v) disclosure. These steps are similar to what obtains with EcoWatch. However, unlike EcoWatch and PROPER, AKOBEN has no independent advisory board involved in the whole process. The absence of such a body raises concerns about credibility and reliability of ratings by both public stakeholders and the participating industries.

\subsection{Rating methodology}

AKOBEN's methodology can be classified into three groups; rating criteria, rating concept and rating rules (EPA Ghana AKOBEN, 2010). The rating criteria consist of seven parameters which are:

1. Legal issues

2. Hazardous waste management

3. Toxic and Non-toxic releases

4. Monitoring and reporting

5. Environmental best practices

6. Community complaints

7. Corporate social responsibility (CSR)

These criteria are very comprehensive and cut across almost all aspects of environmental management and governance issues. This approach differs greatly from the other EPRDs which tend to focus on pollution control and compliance promotion and thus, have their scope covering only the first five parameters listed above. For example, the best environmental practices cover issues related to resource use, renewable energy and carbon emissions. Even though these data are not regulated by the EPA, it helps in creating awareness about an industry's contribution to carbon emissions (INV 300; INV1100). Equally interesting is the CSR criterion which considers companies' policy and performance on social issues. China's programme in Zhenjiang is the only other EPRD programme as far as we know that tends to include social issues in the form of 
community complaints. This is presumably because Zhenjiang is a developed municipality with high income residents who are more likely to be concerned about environmental issues (Wang et al., 2004).

The rating concept provides the guidelines for the use of colours as indicators of performance levels. AKOBEN employs a colour scheme to convey the message to the general public in simple terms. Table 2 below gives a description of the rating system. Red is the colour for the worst performance while Gold is the colour for best performance. In between there is orange, blue and green which stands for unsatisfactory, good and very good respectively. The colours do not necessarily carry any implication for price or penalty but is the EPAs means of encouraging and promote sustainable practices amongst industries.

\begin{tabular}{|c|c|l|}
\hline Rating Level & Performance & General Description \\
\hline RED & POOR & $\begin{array}{l}\text { Has not fulfilled the requirements of LI 1652, and } \\
\text { creates risks from toxics and hazardous wastes } \\
\text { mismanagement and discharges. }\end{array}$ \\
\hline ORANGE & UNSATISFACTORY & $\begin{array}{l}\text { Exceedance of regulatory standards for conventional } \\
\text { pollutants, non-toxics and noise pollution }\end{array}$ \\
\hline BLUE & GOOD & Adequate compliance with environmental standards \\
\hline GREEN & VERY GOOD & BLUE + company is responsive to public complaints \\
\hline GOLD & EXCELLENT & $\begin{array}{l}\text { GREEN + company follows its corporate social } \\
\text { responsibility policies }\end{array}$ \\
\hline
\end{tabular}

Table 2: AKOBEN rating system

Source: www.epaghanaakoben.org [Accessed 10 $10^{\text {th }}$ July, 2011]

The rating rules specify the exact numerical cut off points for each category of the five colour codes. According to AKOBEN officials, the software system has been designed in such a way that there is zero tolerance for non-compliance to legal and hazardous waste management (INV800; INV600). Thus, even if a company complies 99\% with both legal and hazardous waste 
management requirements, the system would still rate the company 'Red'. Moreover, the final rate awarded to an industry is based on the industry's worst performance. This indicates a high level of commitment to environmental protection by the EPA but there are indications that some industries consider this approach too harsh and discouraging (INV 1800; INV 3200; INV3900). The flow chart below provides a pictorial description of the rating rules.

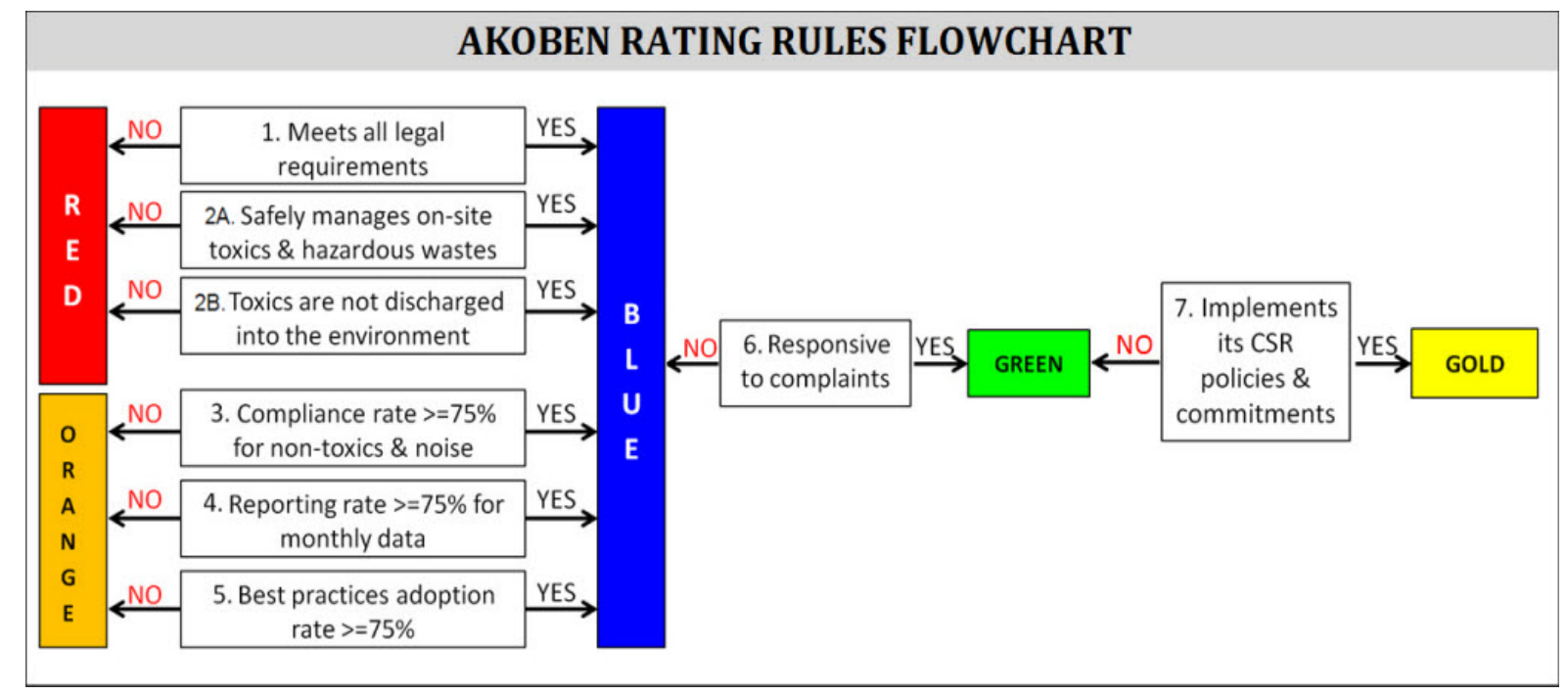

Figure 2: Flowchart showing AKOBEN rating rules

Source: www.epaghanaakoben.org [Accessed 10 $10^{\text {th }}$ July, 2011]

\subsection{Data Collection, Verification and Analysis}

Data used for rating is collected in three main ways. The first, is obtained from the monthly reports submitted to the EPA by industries. Secondly, routine site inspections are undertaken to verify data submitted by industries. Finally, the AKOBEN team embarks on site audits annually to carry out qualitative assessments and collect data that could not be captured in the reports. In some cases, the team incorporates reports and complaints made in the media and by neighbouring communities (INV 100; INV 600). 
After the ratings are compiled, report cards are generated for industries to inform them about their performance against the indicators. On this report card, the overall rate given to the company is shown in addition to the actual percentage obtained. This leads to the first step of disclosure known as the internal disclosure which is done within a month prior to the public disclosure. Unlike the EPRDs in Indonesia, China and Philippines, where there is a grace period between internal disclosure and public disclosure to allow for improvements, AKOBEN's internal disclosure and "grace period" is solely to inform industries about their performance and rectify any discrepancies.

\subsection{Public disclosure component}

After evaluating and analysing the final results, the ratings are released to the public primarily through the press and the internet. The first public disclosure covering data for 2009 was launched in November 2010 by the Minister of Environment, Science and Technology. The ministerial launch is similar to what obtained in Indonesia (PROSPER) and China (EcoWatch) whereby the ratings were announced by the Minister of Environment and President respectively (Afsah, 1997; Kathuria, 2009). Kathuria (2009) argues that the involvement of a highly ranked political figure indicates a strong level of political support which is vital to EPRD implementation.

Various members of the public including traditional leaders, media and NGOs were invited to the launch of the first cycle in November 2010 as well as the second cycle in November 2011. AKOBEN officials stated that the disclosure was well publicised through the use of newspapers and radio to inform the public of the ratings of industries (INV 100; INV 200; INV 600). Additionally, the results were made available on the website for public viewing. 
However, findings from the study reveal that many stakeholders were not very satisfied with the level of publicity currently given to the programme by EPA.

\subsection{Tentative assessment}

As said, AKOBEN is still very much at its infancy so any assessment of its impact would have to be necessarily tentative. However, a basic evaluation of the performance of participating industries for the two disclosure periods reveal that the programme has been somewhat successful in improving the environmental performance of these industries with the 2010 disclosure results showing that most companies have made improvement in virtually each criteria. The chart below (figure 3) includes data on the number of industries that scored the highest rate in each of the criteria listed on the chart. It is quite interesting to note the relative high level of change with respect to the sanction attracting (so called non-tolerant criteria) such as the legal issues and hazard waste management compared to the moral or less stringent criteria like corporate social responsibility.

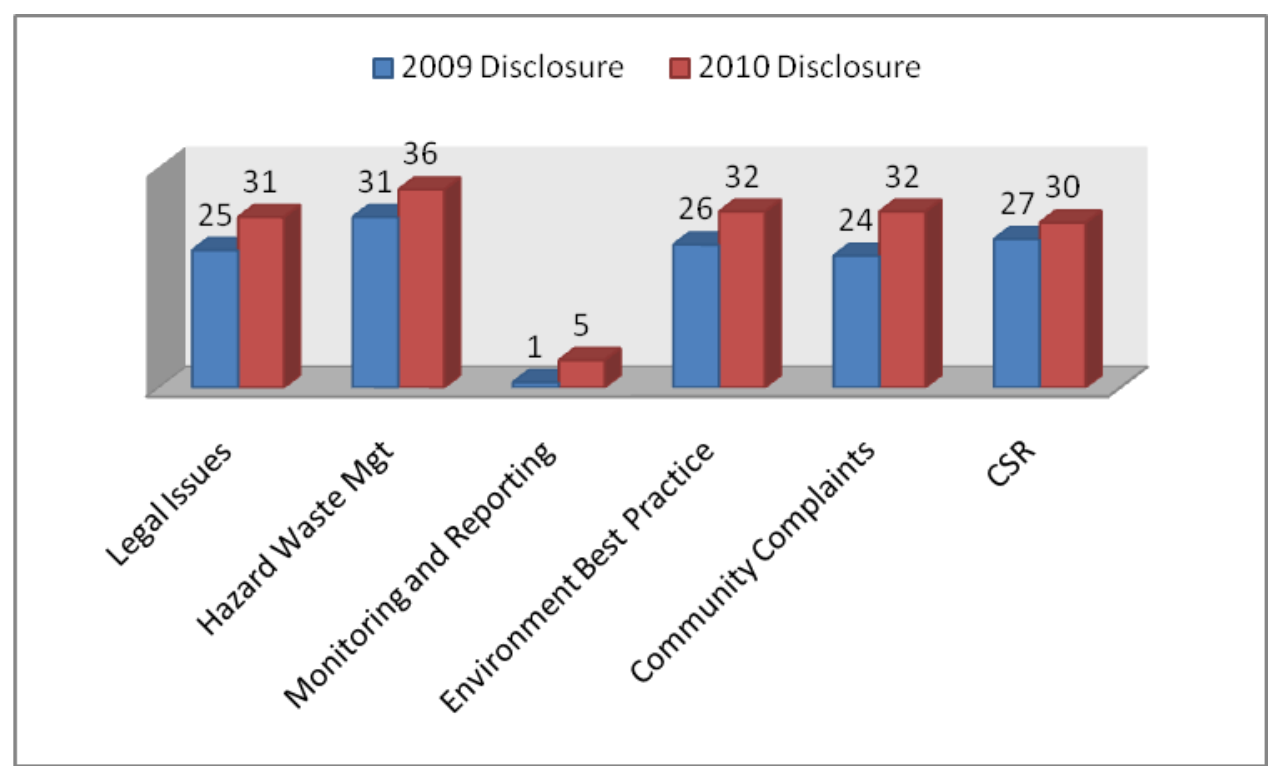

Figure 3: Comparison of industries' performance based on the rating criteria 
Regarding the overall rating performance of the industries for both disclosure periods, the 2010 disclosure recorded modicum improvement with two firms obtaining a blue and green overall score respectively (Colour coding and signifocance of each colour are explained in section 5.5 below on rating methodology below). In the first disclosure program, no firm obtained an overall blue or green rating.

Extant literature suggest that an interesting trend running through many case studies is that EPRD programmes in developing countries have been mainly successful in promoting compliance amongst medium and poorly performing industries and that in most cases, good performing industries were not motivated to attain the highest ratings (Blackman et al., 2004; Lopez et al., 2009). The reason appears to be that the marginal cost for improving performance is often low at the first instance and may involve only simple housekeeping measures. Subsequently, improvement may entail high marginal abatement cost which many companies may not be willing to pay. This leaves one to wonder about the potency of EPRD in driving lasting and far reaching change towards environmental sustainability. Nevertheless, given widespread pollution and poor environmental practice among firms operating in African context, an EDRP such as AKOBEN is welcoming even if it ends up prompting compliance and modicum gestures towards best practice and standards.

\section{SWOT Analysis of Ghana's EPA AKOBEN programme}

Pioneered by the Stanford Research Institute in Harvard between from 1960-1970, SWOT analysis has proven to be a very popular tool for assessing the viability and identifying strategic direction for an organization, policy or practice (Paliwal, 2006). Considering that AKOBEN is a relatively new policy instrument, an analysis highlighting the strengths and weakness as well as 
the potential opportunities and threats could be very useful. This could help in guiding environmental policy makers on what next steps to take to ensure that the project fulfils the aspirations underpinning its establishment.

\subsection{Strengths}

\subsubsection{High-level political support}

A major strength of the AKOBEN project is that it enjoys high level support from within the EPA cadre and more broadly from the Ministry of Environment, Science and Technology. The demonstration of support from the Ministry is evidenced by the personal presence of the Minister of Environment during both disclosure launches. In both ceremonies, the Minister affirmed the commitment of the entire ministry and government to make AKOBEN a big success. The endorsement and support of the Minister is a very critical success component especially since Ghana, like many other African countries, is a highly bureaucratic and top-down society. The involvement of the Minister and the active demonstration of support from the ministry is a necessary condition for ensuring that industries and the general public take the ratings seriously.

Of course it would even be better if in the coming years the EPA can get the president to take part in the launching ceremony or offer public statement in support. Generally, the higher and stronger the political support an ERPD can garner; the better in terms of its success and impact (Afsah, 2006; Paliwal, 2006).

\subsubsection{Comprehensive rating criteria}

The rating criteria of AKOBEN are very comprehensive. The rating criteria consist of seven parameters which cut across nearly all aspects of environmental management and governance 
issues. An analysis of the criteria indicates a strong link to sustainable development if carefully adhered to. Sustainable development refers to a balance between social, economic and environmental needs. The seven indicators arguably seek to cover all these aspects. For example, including CSR in the criteria indicates that the EPA wants to encourage industries to make contributions to the wider development of their host communities and give serious attention to the social dimensions of their business operations. A respondent from one of the industries highlighted this point saying "we have engaged in a lot of CSR activities over the last few years but we have never really kept good records of it because we did not know the EPA would assess us on it, so now we are making sure that we record everything we do so we can also score good points on that criterion (INV 300). The inclusion of Environmental Best Practice as an indicator is demonstrative of the desire of the EPA to push companies beyond the level of minimum compliance with regulation towards world class standard of practice. This criterion also allows the EPA to accommodate important environmental indicators such as energy and resource efficiency into its framework. Hence, it is fair to say that the design of the programme as it stands can help in promoting sustainable development.

\subsubsection{Strengthening of local capacity}

One of the most critical challenges for Africa in the area of environmental governance is lack of local capacity. Absence of trained technical personnel is a major reason hampering effective design and implementation of projects. In the past, there have been many laudable programme initiated with the help of foreign experts which could not be sustained when these expatriates returned to their countries. A vital strength of AKOBEN then is that the programme was started and is being run by a team comprising entirely of local experts from the EPA with consultancy 
services offered by an expatriate (INV100; INV600; INV 700). This will ensure the continuity of the project. Further it will help to ensure organic capacity building within EPA.

\subsubsection{Improved coordination amongst agency workers}

It is often cited that one of the impediments to effective implementation of policies in Africa is the lack of or inadequate coordination amongst various agencies and even amongst various departments within one organisation (ECA, 2003 p.31). In the case of AKOBEN, the team is made up of various officers from the different departments within the EPA. Therefore, even though there is a downside to not having a formal, distinct organizational unit, the coming together of various departments implies increased knowledge sharing and consultation, which is an essential element for ensuring good governance. This can help avoid problems like bribery and corruption that usually emanate from a fragmented approach to work.

\subsubsection{Transparency and inclusiveness}

The AKOBEN process can be considered as a remarkable effort in incorporating transparency in environmental governance in Ghana which can be emulated by other agencies. The idea of publicly disclosing results of industries show the determination of the EPA to be fully transparent about its activities. In the past, some officials would have been very concerned that going public about the poor environmental performance of the companies could lead people to surmise that the EPA was failing in its role to regulate the companies). At the same time, , the process of designing the programme which involved informing industries about the various parameters to be measured also signifies a high level of transparency towards the industries as well. The opportunity granted to industries to input their suggestions into the design demonstrates the element of inclusiveness which is good in terms of the acceptance of the 
programme by the major stakeholders. An industry respondent confirmed this by, saying "the fact that the EPA included us in the whole process showed that the EPA was not imposing something new on us but involved us in their decision making which is very commendable" (INV 300)

\subsection{Weaknesses}

\subsubsection{Absence of specific legal and institutional structures}

Gozun et al. (2011) argue that EPRDs must be strongly institutionalised and have a strong legal backing in order to be effective. Ghana’s EPA AKOBEN programme though backed by certain provisions in the Act 490 and L.I. 1652 has no legislation specifically dedicated to it. Moreover, it is not formally institutionalised because there is no office for the programme within the EPA. Thus even though there is an apparent organisational structure for the AKOBEN team as discussed in the preceding session, this structure is essentially ad hoc and operationalized during the disclosure process or as and when issues arise that are deemed to be beyond the limits of the manufacturing and mining departments (INV 100; INV 200).The lack of a specific legislation and absence of an institution for AKOBEN within the EPA is a major weakness considering the role the government envisages the programme to play in environmental governance in Ghana. One consequence of the current legal status of AKOBEN is lack of clarity about whether the disclosure by companies is voluntary or mandatory. It is not clear what route a participating company can take to address grievance, especially after due internal disclosure processes has taken place, whether AKOBEN is a legal entity that can sue and be sued; and whether a company can decide to opt out of the programme altogether and with what consequences. All of these have consequences relating to inter alia participation, credibility and enforcement. 


\subsubsection{Absence of an independent advisory board}

Unlike the Indonesian PROPER and the Chinese Eco Watch, AKOBEN has no independent advisory body. The lack of any independent advisory board can be viewed as a serious weakness. Even though the process is quite transparent, the level of credibility of the process will be vastly increased if a group of eminent citizens could be brought together to serve as an advisory board. The role of such a board would be to verify results to ensure accuracy and objectivity before the ratings were publicly disclosed. This could increase the acceptance of the ratings by both participating industries and the public. Furthermore, cases from Indonesia and China suggest that the presence of a board also promotes publicity and public participation as the advisory board members are usually made up of representatives of various public bodies.

\subsubsection{Absence of rewards and penalties}

Apart from disclosing the environmental performance of industries to the public, the programme has no incentives or penalties in place. The defence of the AKOBEN team was that EPA already had enforcement powers which could be applied to industries that violated their regulations (INV 600; INV 800). This argument may not hold entirely because AKOBEN considers other criteria that do not fall under the conventional regulations and so applying those sanctions may not be appropriate. The absence of reward or penalty could mean that industries might not be motivated to improve their rating. .In particular, the lack of incentives could discourage industries that are

already performing well in some areas to attain an overall excellent rate (gold). Thus, beyond naming and shaming, AKOBEN may not be effective enough to promote sound environmental management and governance. That said, it should be recognised that the significance of penalty can only be duly ascertained after the evaluation of the actual effectiveness of the programme 
over a decent period has taken place. It is entirely possible that the disclosure process alone can stimulate improvement in the absence of penalty although several studies question the notion that companies would ever make significant sacrifice to achieve high environmental performance without the prospect of fines and sanctions (Clapp, 2008; Helm, 2010).

\subsubsection{Inadequate publicity}

Even though the AKOBEN team insists that the programme was widely publicised, the findings from the field study indicate otherwise with many public respondents, including some industry workers of participating firms claiming they were not aware of the rating project (INV 2200; INV 2500; INV 2700; INV 2900). One public respondent who claimed to be an ardent reader of the Ghanaian national newspaper was very forceful in putting this view across, saying "I think the EPA did not publish the rating in the Daily Graphic, which is the main national. I read this newspaper always and cannot recall seeing the rating” (INV2700). This could imply that the right medium for disclosure may not have been used or that there was inadequate public awareness about the programme before it was launched. For example, according to the internet usage statistics for Africa 2010, the number of internet users in Ghana was about 2.5 million which represents about eight per cent of the total population. Although the use of internet in Ghana and Africa is general is fast increasing, there is still doubt about the use of internet as the main medium for disseminating the ratings to the public. The table below shows the number of visits made from different countries within six months of publishing the first results on the website. Even though the highest visits were from Ghana, the number is still quite small relative to total internet users in the country. 


\begin{tabular}{|c|c|c|c|c|c|c|c|c|c|}
\hline \multicolumn{6}{|c|}{1,319 visits came from 67 countries/territories } & \multicolumn{4}{|c|}{ Nov 24, 2010 - Mar 14, 2011} \\
\hline \multicolumn{2}{|c|}{$\begin{array}{l}\text { Visits } \\
1,319 \\
\% \text { of Site Total: } 100.00 \%\end{array}$} & \multirow{2}{*}{$\begin{array}{l}\text { Pages/Visit } \\
2.72 \\
\text { Site Avg: } 2.72(0.00 \%) \\
\text { mritory } \approx\end{array}$} & \multirow{2}{*}{$\begin{array}{l}\text { Avg. Time on Site } \\
\text { 00:03:09 } \\
\text { Site Avg: 00:03:09 (0.00\%) } \\
\qquad \begin{array}{l}\text { Visits } \downarrow\end{array}\end{array}$} & \multicolumn{3}{|c|}{$\begin{array}{l}\text { (7) New Visits } \\
77.63 \% \\
\text { Site Avg: } 77.63 \%(0.00 \%)\end{array}$} & (7) & \multicolumn{2}{|c|}{$\begin{array}{l}\text { Bounce Rate } \\
58.91 \% \\
\text { Site Avg: } 58.91 \%(0.00 \%)\end{array}$} \\
\hline & Detail Levet Country/Ter & & & & PagesNisit & Avg. Time on Site & & $\%$ New Visits & Bounce Rate \\
\hline 1. & Ghana & & 442 & & 3.07 & $00: 04: 56$ & & $73.98 \%$ & $48.42 \%$ \\
\hline 2. & United States & & 225 & & 3.41 & $00: 03: 00$ & & $64.00 \%$ & $49.78 \%$ \\
\hline 3. & United Kingdom & & 87 & & 3.23 & $00: 03: 09$ & & $73.56 \%$ & $60.92 \%$ \\
\hline 4. & France & & 77 & & 1.70 & $00: 00: 43$ & & $92.21 \%$ & $81.82 \%$ \\
\hline 5. & Switzeriand & & 67 & & 1.75 & $00: 00: 39$ & & $94.03 \%$ & $73.13 \%$ \\
\hline 6. & Germany & & 56 & & 1.96 & $00: 01: 25$ & & $91.07 \%$ & $71.43 \%$ \\
\hline 7. & (not set) & & 52 & & 1.50 & $00: 01: 55$ & & $80.77 \%$ & $75.00 \%$ \\
\hline 8 & South Africa & & 36 & & 2.39 & $00: 02: 56$ & & $91.67 \%$ & $66.67 \%$ \\
\hline 9. & Canada & & 31 & & 3.29 & $00: 04: 45$ & & $64.52 \%$ & $54.84 \%$ \\
\hline 10. & Colombia & & 27 & & 2.74 & $00: 03: 55$ & & $48.15 \%$ & $62.96 \%$ \\
\hline
\end{tabular}

Table 3: Number of visits made on the AKOBEN website

Source: AKOBEN team, 2011

This confirms the argument made by Dasgupta et al. (2006) and Gozun et al. (2011) about the need to employ the most suitable medium for disseminating results based on the socio-economic and cultural characteristics of citizens. In Ghana, it may be possible to increase awareness of results by involving churches, traditional rulers and community groups. In addition, defining the target group as the general public may not be such a clever idea in a context where people are only now becoming increasingly aware of environmental issues. In order to obtain better response it might be better to have a more targeted group and medium of publicity. Finally, the lack of any public sensitisation campaign after the disclosure meant that the public may not be well empowered to participate in governance even if they were aware of these ratings.

\subsubsection{Overall rating and Timing of disclosure}

Although the main aim of the programme is to promote compliance, the use of the worst rating as the overall score does not convey the right message to the public. For example, if an industry scored "red" in one of the sensitive categories described in section 5.5 but performed well in the 
others, the overall summary score was a red. While the use of this rating communicates a sense of seriousness on the part of EPA, it might be very discouraging for industries. In fact, many respondents echoed similar concerns of unfairness especially because the report cards given by the EPA includes their disaggregated score showing performance for each rating criterion as well as their overall performance. This report card, in essence, provides a better indication of performance than what is disclosed to the public.

Moreover, many industry respondents complained about the absence of a grace period from the internal disclosure phase to the public disclosure and suggested that such a provision be included to the process. This corroborates the argument by Wang et al. (2004) that the allowance of time between the pilot and public disclosure contributed to the success of the Green Watch programme, in which case, some industries were able to improve their ratings before it went public offically. But one must be wary of such an approach because it may not be a sustainable approach to improving environmental performance if the only driver for change is to appear as good to the public and nothing more.

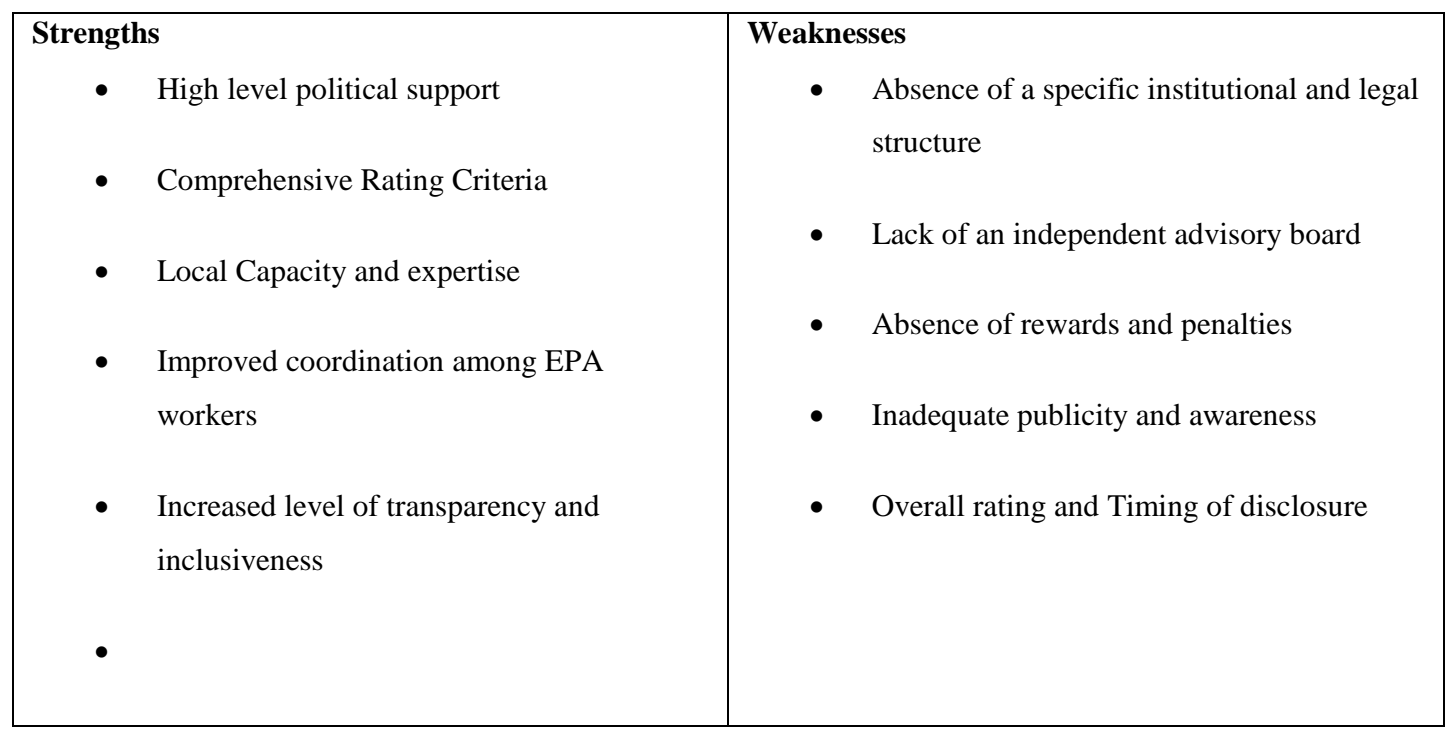




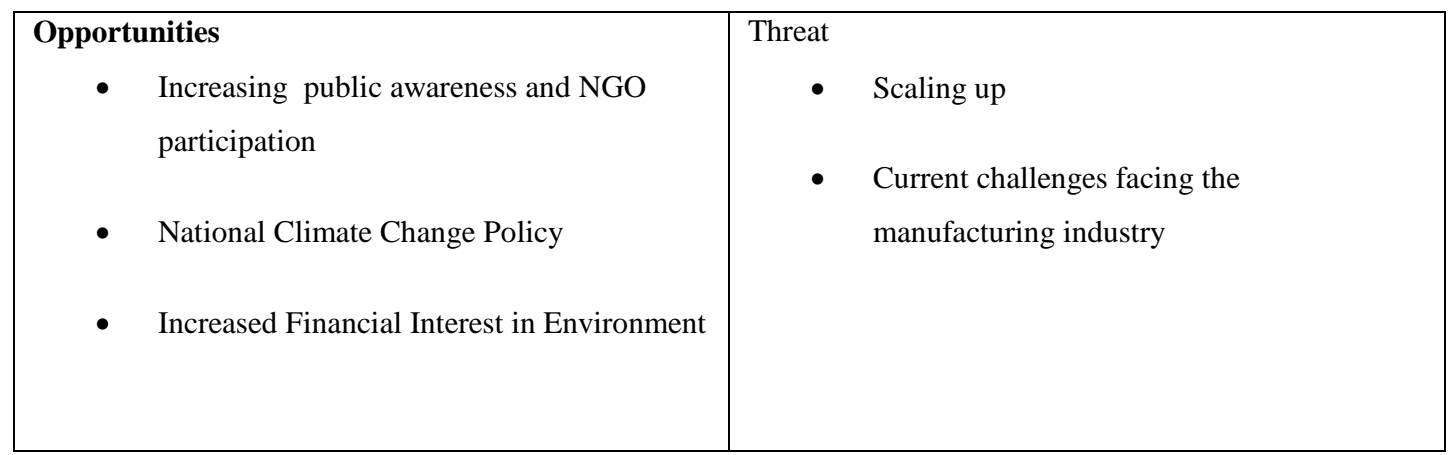

Table 4: SWOT analysis of EPA AKOBEN Programme

\subsection{Opportunities}

Having discussed the weaknesses of the AKOBEN programme, there are some external factors that can provide opportunities for the success of the AKOBEN programme.

\subsubsection{Increasing public awareness and NGO participation}

In recent years, many Ghanaians are becoming increasingly aware of environmental issues. This has been made possible by the proliferation of mass media, which is widely used as a platform for sensitising the public about environmental issues. Moreover, some community members are becoming increasingly vocal and expressing their dissatisfaction about various activities that degrade the environment. Additionally, some environmental NGOs in Ghana are creating awareness about environmental issues by challenging industries and ensuring that environmental justice is achieved. For example, one NGO respondent indicated by saying "these ratings adds a lot of credence to the assertions made by us and local communities about the way the environment is degraded by industries especially the mining sector” (INV 4100). This response along with a few others reveals a potential for coordination between EPA and other like-minded organisations and individuals. A major opportunity for EPA then is to effectively leverage this growing environmental awareness and activities of NGOs in the implementation of AKOBEN. 
Doing so will vastly increase the publicity of the programme and its impact on both companies and the larger society.

\subsubsection{National climate change and low carbon development policy}

There is opportunity for AKOBEN to become an important tool in Ghana's national climate change policy framework. As part of Ghana's climate change mitigation efforts, certain objectives have been set for the various industry sectors. The goals for manufacturing industries are to institute energy efficiency measures in their operations and to improve upon their resource efficiency to promote sustainable production and consumption (Cameron et al., 2011 p. 5). Since the AKOBEN rating criteria also covers some of these factors, the programme could be easily adapted as a part of the policy tool for governing climate change in Ghana. Doing so is likely to give AKOBEN visibility within the climate change community. It will also elevate the status of Ghana as one of the few developing countries that has a clear tool for mainstreaming climate change into the operation of industries within its jurisdiction. Energy and resource efficiency is also a win-win for communities and companies since it simultaneously reduces environmental externalities and the cost of business operation.

\subsubsection{Interest in environmental issues by the financial sector}

In recent times, some financial institutions are beginning to incorporate environmental considerations in making decisions related to credit facilities for clients. For example some banks and insurance companies require industry borrowers to reveal information about their potential carbon and environmental impact alongside intended mitigating actions. This information is subsequently taken into account in making lending decisions (Weber et al., 2010). The increasing awareness of environmental issues amongst financial institutions can serve as an opportunity for 
AKOBEN to be sustained and made relevant in company's investment decisions. At the same time, financial institutions like the banks can also use the ratings from AKOBEN to cross check and further verify industries' claim regarding their environmental performance when they are looking to borrow money.

\subsection{Threats}

\subsubsection{Scaling up}

The ultimate aim of the EPA is to scale up AKOBEN to include all industries in Ghana. This ambition has serious implications in terms of both financial and logistical costs. For one, the increased demand for monitoring and verification of all participating industries would require that more persons are employed and trained. In addition, even though some proponents of EPRD programme argue that it is a relatively cheap instrument for regulations, others such as Dasgupta et al (2006) suggest that processes like monitoring, data entry, data analysis and the disclosure itself can be expensive and perhaps equal to the costs associated with conventional regulations. This may be particularly true for Ghana when they decide to include about 2000 industries that are already operating in the country at the moment. Moreover, the decision to scale up the programme could result in some industries submitting wrong reports for evaluation as the team might not be able to go round to verify the accuracy of data. This in turn could lead to inaccurate ratings of industries and potentially undermining the integrity of the whole process. 


\subsubsection{Current challenges facing the manufacturing industry}

Many industries in Ghana currently face several challenges some of which has been exacerbated by the global economic downturn. These challenges include lack of access to credit facilities, high costs of raw materials, competition from imported goods and high costs of credits. These challenges could lead to industries becoming more concerned about the economic and financial survival of their operations at the expense of environmental considerations. Such a situation can affect both the willingness of industries to participate and the robustness of the data submitted.

\section{Suggestions for improving the programme}

To improve the program, the EPA should push the government of Ghana to establish a strong legislative framework for AKOBEN. This should be done in consultation with the Ministry of Environment Science and Technology since it is the policy formulating body for the environment sector. Within the EPA itself, it is important to establish a clear institutional framework for the programme. The EPA should seriously consider establishing a separate office for the AKOBEN team with clearly mandated functions so as to avoid unnecessary conflicts with other roles that are required of team members under their respective employment positions. In this way, the team would be adequately equipped to perform their functions as expected.

Moreover, The EPA should seriously consider constituting an independent advisory board for the AKOBEN programme. Cases from Indonesia and Philippines indicate that setting up an independent advisory body has multiple benefits. It is important to think carefully when drawing up the membership of such a board. The board should in principle comprise stakeholders that are interested in promoting good and transparent environmental governance in the country. It could be helpful to draw membership from high profile organisations such as 
banks, environmental NGOs, media, Association of Ghana Industries and other community leaders. This can help increase credibility and accountability which is very essential for such a programme to be accepted by the general public.

There should be increased public education and awareness campaigns for the general public to explain the ratings. Furthermore, the EPA could create a platform that would encourage and empower the general public to participate in decision making by being able to lodge complaints and seek environmental justice if the need arises. Also, there should be increased publicity if the EPA seeks to maintain the target group as the general public. This can be done by finding out which medium is widely used and accepted by the majority stakeholders or tailoring the various media to the appropriate target group. For example, the local radio stations can be used for disseminating results to community members who may not be literates. Other groups that could be involved might be churches, traditional leaders and community youth groups. All these can help build the capacity of stakeholders and empower them to participate in environmental governance.

Finally, EPA should consider going beyond just 'naming and shaming' to providing incentives to good performing industries. These incentives could be tied to other government policies like concessionary rates on any imports or machinery used directly for environmental management. Also, awards could be given to these industries during the World Environment Day that is celebrated annually. Finally, the use of labels certified by the EPA can be placed on the products by manufacturing industries that can serve as a premium and increase the public awareness of company's environmental performance. It might be worthwhile for the AKOBEN team to allow a grace period for industries between the time of internally disclosing the ratings and public disclosure to enable industries improve upon their performance. 


\section{Conclusion}

The article has shown that the AKOBEN programme is a very useful complementary tool to traditional command and control environmental governance mechanism in Ghana. Indeed, Ghana's EPA AKOBEN programme is a laudable initiative by the EPA which if managed and implemented effectively could lead to the achievement of sustainable development and improved environmental governance. The detailed description of the programme reveals that the programme possesses many of the essential components needed for an EPRD programme to be effective in promoting compliance to environmental regulation. The SWOT analysis indicates that the programme has many strengths and opportunities that make it a worthwhile policy instrument in environmental governance. These include high level political support, comprehensive rating criteria and transparency of methodology. Conversely, it also contains weaknesses that could undermine the success of the programme. The most important of these is absence of clear regulatory framework and poor institutionalization. Some recommendations have been suggested to mitigate the weakness of AKOBEN and shore up its credibility among the general public. While the expansion of participating industries would be desirable in the long run, the key is to get the timing right. It may be better to focus on consolidating the programme and increasing publicity for now and to build on the success more slowly.

\section{References}

Abbey, E (2011) “Internet Usage in Ghana Increases”, Business Guide, May 3, 2011[Online].

Available at http://www.businessguideghana.com/?p=3407. [Accessed $28^{\text {th }}$ August, 2012]

Afsah, S. and Ratunanda, D. (1999), “Environmental Performance Measurement and Reporting in Developing Countries: the case of Indonesia's Program for pollution control evaluation and rating (PROPER), in Bennett, M.,James. P. and Klinkers, L. (Ed.), Sustainable measures: Evaluation and Reporting of Environmental and Social Performance, Sheffield, Greenleaf Publishing Ltd, pp. 185-201. 
Afsah, S., Laplante, B. and Wheeler, D. (1997), Regulation in the Information Age: Indonesian Public Information Program for Environmental Management, Washington DC: World Bank, Policy Research Paper.

Afsah, S. (2006), Good Governance through Performance Rating and Disclosure: The Case of Indonesia's PROPER Program. Performeks LLC, pp1-4

Allotey et al., (2011), Integration of Environmental Disclosure into Regulatory Management: the case of AKOBEN Environmental Rating Program, in Proceedings of the 9th International Conference on Environmental Compliance and Enforcement, British Columbia, 20-24 June, 2011.

Berg, B.L. (2009) Qualitative Research Methods for the Social Sciences. $7^{\text {th }}$ ed. Boston: Allyn \& Bacon.

Blackman, A., Afsah, S. and Ratunanda, D. (2004), "How do Public Disclosure Pollution Control Programme Work? Evidence from Indonesia”, Human Ecology Review, Vol. 11 No. (3), pp. 235-246.

Cameron, L., van Tilburg, X. and Würtenberg. (2011), Policy Brief- NAMAs and the Ghana Shared Growth and Development Agenda 2010-2013, pp1-12.

Clapp, J. (2008), “Illegal GMO releases and corporate responsibility: Questioning the effectiveness of voluntary measures.” Ecological Economics, Vol. 63 No. (2-3), pp. 348358.

Strategic Environmental Assessment of Ghana Poverty Reduction Strategy (2004) Content Report. Environmental Protection Agency, Accra, Ghana.

Dasgupta, S., Wang, H. and Wheeler, D. (2007), “Disclosure Strategies for Pollution Control. In: Tietenberg, T. and Folmer, H. (Ed.), The International Yearbook of Environmental and Resource Economics. Massachusetts: Edward Elgar Publishing, pp. 93-119.

Domfeh, K. (2003), “Compliance and Enforcement in Environmental Management in Ghana: A case of Mining in Ghana”, Environmental Practice Vol. 5, pp. 154-165.

Economic Commission for Africa (ECA) (2003), Public Sector Management Reform pp. 1-75.

Environmental Protection Agency (EPA)-Ghana (1994), “Act 490, 1994”.

Environmental Protection Agency (EPA)-Ghana (2004), State of the Environment Report. Environmental Protection Agency, Accra, Ghana.

Environmental Protection Agency (EPA)-Ghana (2010), AKOBEN Rating and 
Disclosure Programmeme. Available at http://www.epaghanaakoben.org/. [Accessed on $5^{\text {th }}$ June, 2011]

Gozun, E.G., Laplante, B. and Wang, H. (2011), “Design and Implementation of Environmental Performance Rating and Public Disclosure Programmemes- A summary of Issues and Recommendations based on Experiences in East Asian Countries", Washington DC: World Bank Policy Research Working Paper Series 5551. [online]. Available at http://www.wds.worldbank.org/servlet/WDSContentServer/WDSP/IB/2011/01/25/00015 8349_20110125153118/Rendered/PDF/WPS5551.pdf [Accessed 10th June, 2011]

Gupta, A. (2010), “Transparency in Global Environmental Governance: A Coming of Age?” Global Environmental Politics Vol. 10, No. 3, pp. 1-9.

Gupta, A. (2008), “Transparency under Scrutiny: Information Disclosure in Global Environmental Governance”, Global Environmental Politics, Vol. 8 No. 2, pp. 1-7.

Haufler, V. (2010), "Disclosure as Governance: The Extractive Industries Transparency Initiative and Resource Management in the Developing World.” Global Environmental Politics, Vol. 10, No. 3, pp. 53-73.

Helm, D. (2010) Government Failure, Rent-seeking, and Capture: The Design of Climate Change Policy, Oxford Review of Economic Policy. Vol. 26 No. 2, pp. 182-96.

Jin, Y., Wang, H. and Wheeler, D. (2010), “The Impact of Environmental Performance Rating and Disclosure: An Empirical Analysis of perceptions by Polluting Firms' Managers in China”, World Bank Policy Research Working Paper Series 5419, Washington DC, USA. 5419.

Kathuria, V. (2006), “Controlling water pollution in developing and transition countries: Lessons from three successful cases”, Journal of Environment Management, Vol. 78. Pp. 405-426.

Kathuria, V. (2009), Public Disclosure: Using Information to Reduce Pollution in Developing Countries”, Environment, Development and Sustainability, Vol. 11, pp. 955-970.

Kolk, A., and Lenfant, F. (2010), "MNC Reporting on CSR and Conflict in Central Africa." Journal of Business Ethics, Volume 93, Supplement 2, pp. 241-255.

Lopez, G.J., Sterner, T. and Afsah, S. (2009), "Public Disclosure of Industrial Pollution: The PROPER Approach for Indonesia? University of Gothenburg", Working Papers in Economics No. 414.

National Development Planning Commission (2010), “Medium-Term National Development Policy Framework: Ghana Shared Growth and Development Agenda (GSDA), 20102013 Volume 1: Policy Framework

Paliwal, R. (2006), "EIA Practice in India and its evaluation using SWOT Analysis", Environmental Impact Assessment Review, Vol. 26, pp 492-510 
Powers, N., Blackman, A., Lyon, T.P and Narain, U. (2008) Does Disclosure reduce Pollution? Evidence from India's Green Rating Project. Resources for the Future: Environment for Development Discussion Paper No. 27.

Saldana, J., 2009. The Coding Manual for Qualitative Researchers. London: Sage Publications Ltd.

Tietenberg, T. (1998), “Disclosure Strategies for Pollution Control”, Environmental and Resource Economics, Vol.11 No. 3-4, pp. 587-602.

Wang, H., Bi, J.,Wheeler, D., Wang, J.,Cao, D., Lu, G. and Wang, Y. (2004), “Environmental Performance Rating and Disclosure: China’s Green Watch Program.” Journal of Environmental Management, Vol. 71, pp.123-133.

Weber, O., Scholz, R.W. and Michalik, G. (2010), “Incorporating Sustainability Criteria into Credit Risk Management”. Business Strategy and the Environment, Vol. 19, pp. 39-50.

\section{Bio-notes of Authors}

Chukwumerije Okereke ( $\mathrm{PhD}$, University of Keele) is a Reader in Environment and Development at the School of Human and Environmental Sciences, University of Reading, UK. Before joining Reading he was a Senior Research Fellow and Head, Climate and Development centre at the Smith School of Enterprise and the Environment, University of Oxford. He remains a Visiting Fellow at the Smith School and Oxford University's Environmental Change Institute (ECI). His research focuses on the links between global climate governance systems and international development. His recent research has addressed the drivers for corporate climate strategies among UK energy intensive companies and the relationship between government policy and corporate carbon management. He has published widely on the political economy and ethical dimensions of the international climate governance regime in journals such as the California Management Review, Nature, Organization Studies, European Management Journal, Global Environmental Change and Global Environmental Politics.

Adwoa Boatemaa Darko-Mensah is a graduate of University of Oxford (MSc -Environmental Change and Management) and Kwame Nkrumah University of Science and Technology (BSc Land Economy). She held a graduate internship position at the African Development Bank in Tunisia. She has won several academic excellence awards including the Commonwealth Shared Scholarship and the Ebenezer Acquaye award by the Ghana Institute of Surveyors for being the overall best student on the Land Economy programme. 